\title{
Shallow-water gaseohydrothermal plume studies after massive eruption at Panarea, Aeolian Islands, Italy.
}

\author{
T. Tudino ${ }^{1,2}$, G. Bortoluzzi ${ }^{3}$, S. Aliani ${ }^{1}$
}

\begin{abstract}
Marine water dynamics in the near field of a massive gas eruption near Panarea (Aeolian Islands volcanic arc, SE Tyrrhenian Sea) is described. ADCP current-meters were deployed during the paroxysmal phase in 2002 and 2003 a few meters from the degassing vent, recording day-long timeseries. Datasets were sorted to remove errors and select good quality ensembles over the entire water column. Standard deviation of error velocity was considered a proxy for inhomogeneous velocity fields over beams. Timeseries intervals had been selected when the basic ADCP assumptions were fulfilled and random errors minimized. Backscatter data were also processed to identify bubbles in the water column with the aim of locating bubble-free ensembles. Reliable timeseries are selected combining these data. Two possible scenarios have been described: firstly, a high dynamic situation with visible surface diverging rings of waves, entrainment on the lower part of the gas column, detrainment in the upper part and a stagnation line (SL) at mid depth where currents were close to zero and most of the gas bubbles spread laterally; secondly, a lower dynamic situation with water entraining into the gas plume at all depths and no surface rings of diverging waves. Reasons for these different dynamics may be ascribed to changes in gas fluxes (one order of magnitude higher in 2002). Description of SL is important to quantify its position in the water column and timing for entrainment-detrainment, and it can be measured by ADCP and calculated from models.
\end{abstract}

Keywords:

High-flux gas venting, ADCP, numerical modeling, hydrothermalism

\section{Introduction}

Emissions of gas, geothermal-heated water and ion-enriched fluids from hydrothermal vents could be large enough to create upward convective plumes in the ocean. Once released into seawater, fluids are advected downstream and diluted depending on environmental energy and dynamics (Lupton, 1995; Tivey et al., 2002).

The consequences of such emissions for the marine environment include nutrient enrichment (Robinson, 2000), transportation of particles and chemicals over considerable distances (Bayona et al., 2002; Svensson et al., 2004; Rona et al., 2006) and toxic effects on fishes and other marine life (Thiermann et al., 1997). The mixing of seawater with vent fluids changes geochemical processes and mineralization patterns (Rona et al., 2006) as well as seawater composition which increase the amount of $\mathrm{CO}_{2}$, sulfur and metals (Allard et al., 1991; Kadar et al., 2012).

Water dynamics in the near field of shallow-water hydrothermal vents is characterized by interactions of seawater with free gas due to low hydrostatic pressure typical of shallow areas. This is a scenario different from deep sea where mainly liquid

Email addresses: tt282@exeter.ac.uk (T. Tudino), giovanni.bortoluzzi@ismar.cnr.it (G. Bortoluzzi), stefano.aliani@ismar.cnr.it (S. Aliani)

${ }^{1}$ ISMAR CNR, Forte S.Teresa Pozzuolo di Lerici, La Spezia, Italy

${ }^{2}$ University of Exeter, The Queen's Dr, Exeter, Devon, UK

${ }^{3}$ ISMAR CNR, Via Gobetti 101, Bologna, Italy fluids mix seawater with an entrainment ratio of about $10^{4}: 1$ during the formation of neutrally buoyant plumes (German and Von Damm, 2006). Literature on shallow plumes (less than $200 \mathrm{~m}$ depth) is poor compared to deep sea ones (Pichler et al., 1999; Wenzhöfer et al., 2000; Tarasov et al., 2005) and comprehension of entrainment and interaction processes of gas plumes with seawater is still challenging.

Different emissive scenarios of bubbles have been reported at shallow vents: i) gas diffuses from the permeable seabed in widespread small bubbles creating local peculiar bottom landscapes (O'Hara et al., 1995; Dando et al., 2000); ii) large gas bubbles escape through fissures in the rocks along fault lines, affecting the environment over horizontal distances of up to hundred meters (Aliani et al., 1998; Dando et al., 2000; Bayona et al., 2002; De Biasi and Aliani, 2003); iii) gas emissions occur when eruptions come from single spots (eruptive plumes). In this last case, the amount of free gas released can be so large that visible columns of rising bubbles reach the surface, affecting SCUBA diver buoyancy and seafloor stability (Aliani et al., 2010).

Acoustic instruments have already been used in hydrothermal systems to measure gas (Heinicke et al., 2009) and fluids (Jackson et al., 2003). Acoustic Doppler Current Profilers (ADCP) can be used to measure 3D flow characteristics along a vertical section of regularly spaced cells (bins) over a fixed timespan. Modern broadband ADCPs use four different transducers to calculate Doppler shift travel time, using horizontal homogeneity as a basic assumption with counterposed trans- 
ducers measuring the same flow. However, ADCPs have also been used when that assumption does not hold, as in turbulent flows (Nystrom et al., 2007; Sousa, 2007), in $\mathrm{CH}_{4}$ plumes (Linke et al., 2010) and for underwater bubble detection (Wang et al., 2011).

In 4 beam broadband ADCP measurements, error velocity is the difference between two estimates of vertical velocity (Gordon, 1996). If there are differences in the direction of one beam compared to the others, vertical velocity is affected and error velocity is recorded. In standard processing, error velocity is a useful tool to either accept or reject ADCP data as it provides information on the horizontal homogeneity assumption required to calculate velocities (Gordon, 1996).

Models of gas plumes and their interactions with water were developed theoretically and in the laboratory by McDougall (1978); Leifer et al. (2000); Brevik and Kristiansen (2002); McGinnis et al. (2004). Since then, they have been proposed to describe gas-water plumes from methane underwater spillages or for environmental restoration (Solomon et al., 2009; Linke et al., 2010).

The aim of this paper is to describe the water dynamics in the near field close to a gas/water hydrothermal eruptive plume using ADCP data. A critical view of ADCP data acquisition and processing is proposed to improve ADCP setting mode for non standard situations. Measurements have been tested and compared to a theoretical model.

\section{Materials and methods}

\subsection{Study area}

On 2002-11-02 a gaseohydrothermal explosive eruption took place close to Bottaro islet (Panarea, Aeolian islands, Tyrrhenian Sea) and lasted up to the end of 2003 with a continuous flux. Including smaller vents, a total area of about $1 \mathrm{~km}^{2}$ was affected (Caliro et al., 2004; Anzidei et al., 2005; Esposito et al., 2006; Capaccioni et al., 2007).

The gas-water plume reached the surface from a main crater (20 x 10m wide) with bottom depth at $14.5 \mathrm{~m}$. Visual observation by divers, surface estimates and Reson 8125 Multibeam soundings provided descriptions of the plume from the early stages of eruption. The gas plume was present both in 2002 and 2003. Fig. 1 reports a sketch of the time evolution of the plume and the seafloor morphology from multibeam data as well as position of instruments.

The plume was columnar in shape from bottom to surface, with diameter that changed according to flux variations. Most of the larger bubbles $(>10 \mathrm{~cm}$ diameter) were entrained into the ascending column and only a few small ones $(<1 \mathrm{~cm})$ were free rising in the water column. At surface, large bubbles generated radially-directed currents, also visible as diverging rings of small waves and bubbles (fig. 2).

In 2002 gas fluxes were estimated at approximately $9.3310^{8} 1$ day $^{-1}$ and in 2003 estimates were one order of magnitude lower $\left(0.7210^{8} 1 \mathrm{day}^{-1}\right)$ (Aliani et al., 2010). After 2003, a continuous gas plume from bottom to surface was not found anymore and the plume became cone-shaped. During recent surveys, diffuse

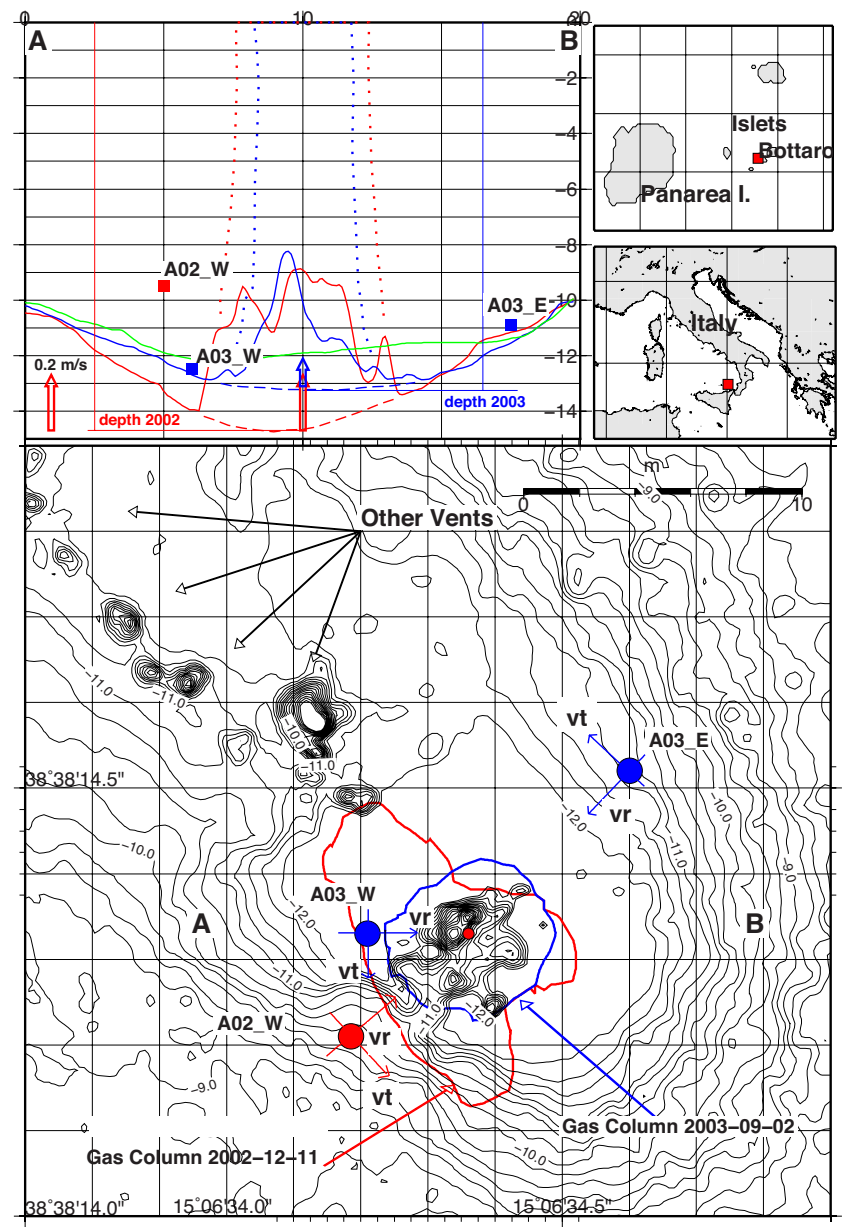

Figure 1: Upper left panel shows bathymetric profiles from 2002 (red), 2003 (blue) and 2012 (green) along the section from A to B. Red and blue filled lines above sea bottom show the outer envelope of gas from multibeam data; dotted lines show the border of the gas column from divers observations. Lower panel shows the bathymetry from 2003 survey (Anzidei et al., 2005; Aliani et al., 2010). Red dot is A02_W ADCP, blue dots are A03_E and A03_W. Contour lines show the footprint of the gas plume in 2002 (red) and 2003 (blue). Arrows superimposed on red and blue dots (2002 and 2003 respectively) identify the tangential $\left(v_{t}\right)$ and the radial $\left(v_{r}\right)$ velocities for every ADCP after rotation of $u, v$ coordinates. Direct Mercator Projection, grid 0.1 Arcsec. 


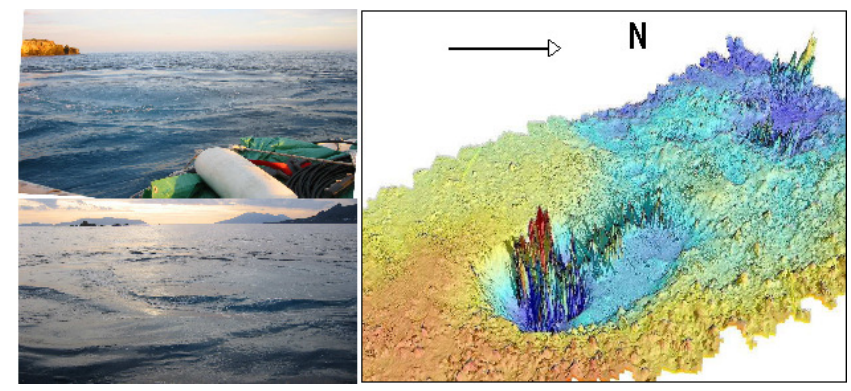

Figure 2: Images from the eruption. Left panels) surface vortex as visible from boats (December 2002). The large surface whirlpool was present also during 2003 experiment, although reduced in size and intensity. Right panel) 3D reconstruction of the bathymetry and gas column (SE view) from multibeam data (December 2002).

seepage has been found and the deeper part of the crater has been almost filled by sediments (Dialti et al., 2013).

\subsection{Instruments and setup}

In 2002-12 and 2003-09, the gas column was visibly extending from the seabed to the surface (fig. 1). ADCP measurements were collected in the near field of the gas plume. The near field was assumed to be the area within a distance from the plume corresponding to half-water depth.

On 2002-12-11, SCUBA divers accurately leveled on the seabed one Teledyne RDI Workhorse WH-1200 KHz ADCP (A02_W) to the western side of the plume at $9.5 \mathrm{~m}$ depth. 19 cells (bins), regularly spaced along the vertical, were collected starting from $10: 16 \mathrm{~h}$ to $15: 26 \mathrm{~h}$ in the following day. The bin size was set to $0.5 \mathrm{~m}$ and the sampling rate was $300 \mathrm{~s}$.

On 2003-09-02, divers deployed two ADCPs (a WH-1200 $\mathrm{KHz}\left(\mathrm{A} 03 \_\mathrm{W}\right)$ and a WH-600 KHz (A03_E)) to the West and East of the plume at $12.5 \mathrm{~m}\left(\mathrm{~A} 03_{-} \mathrm{W}\right)$ and $10.5 \mathrm{~m}$ (A03_E) depth. ADCPs measured 25 and 21 bins, respectively. A03_W recorded from 12:18h to 19:03h and A03 E recorded from $12: 27 \mathrm{~h}$ to $19: 12 \mathrm{~h}$. A similar set up was used the following day. The distances from the centre of the gas column were about 5m (A02_W), 4m (A03_W) and 8m (A03_E). Position of instruments has been reported in fig.1.

Data collection was according to RDI factory recommendations concerning bin size, blank after transmission, power and currents were recorded with usual setting EX11111 (Gordon, 1996). The raw beam data were processed by the internal software and recorded output was an average distribution along the ADCP vertical.

ADCP "earth-centered" data were read by the Teledyne RDI WinADCP package, and analyzed by Matlab ${ }^{\circledR}$ and Octave (Eaton et al., 2008) scripts. Maps were produced with GMT (Wessel and Smith, 1995).

\subsection{Uncertainties in ADCP measurements}

Two main sources of error have been reported for ADCP datasets: i) the physical configuration of the instrument transducers; ii) the limitations of signal generation/recording and processing algorithms (Nystrom et al., 2007).
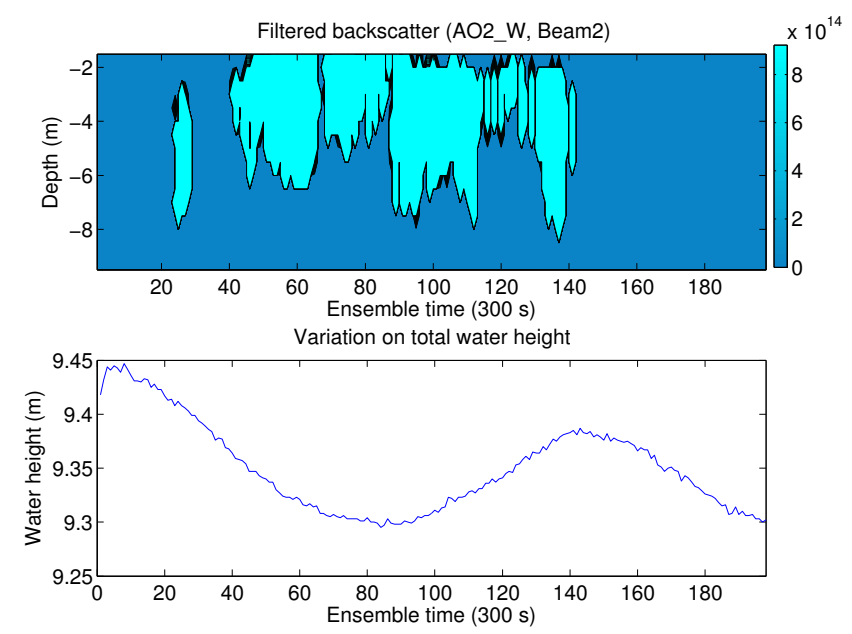

Figure 3: Filtered backscatter (above) and water height (below) from A02_W. Backscatter data were filtered removing gradient due to beam attenuation. Periods with high scattering properties were highlighted.

The physical configuration of the transducers causes errors in the resolved velocities measured in the inhomogeneous flow. The Janus configuration ( 4 acoustic beams paired in orthogonal planes and inclined at a fixed angle to the vertical, usually 20-30 degrees), provided as default in Workhorse ADCPs, was found to be the best instrument layout.

The signal generation and the processing algorithm include errors in temporal and spatial resolution of collected data and on Doppler-shift measurements. The temporal and the spatial data resolutions must be consistent with the process to measure, e.g. Nyqvist frequency, and the time scales must agree with the sampling rates and the size of the measured bins algorithms (Gilcoto et al., 2009).

Doppler-shift measurement errors are essentially errors in measuring the radial-beam velocity and take two forms: i) random inaccuracies in measurement of the Doppler-shift, ii) nonrandom errors caused by misalignments and limitations of the measurement technique. Both forms of errors can have important consequences on the data in the unusual environmental conditions, and are strongly dependent on the specific processing algorithms used by the instrument.

The random error is uncorrelated from ping to ping and averaging reduces the standard deviation of the error by the square root of the number of pings. Due to the fact that the random errors generated internally in the ADCP are typically an order of magnitude smaller, the external random error sources (i.e. turbulence) can dominate.

The random errors can be estimated by computing the standard deviation of the error velocity as they are independent from beam to beam and the error velocity is scaled by the ADCP to give the correct magnitude of the horizontal velocity random errors (Gordon, 1996). 


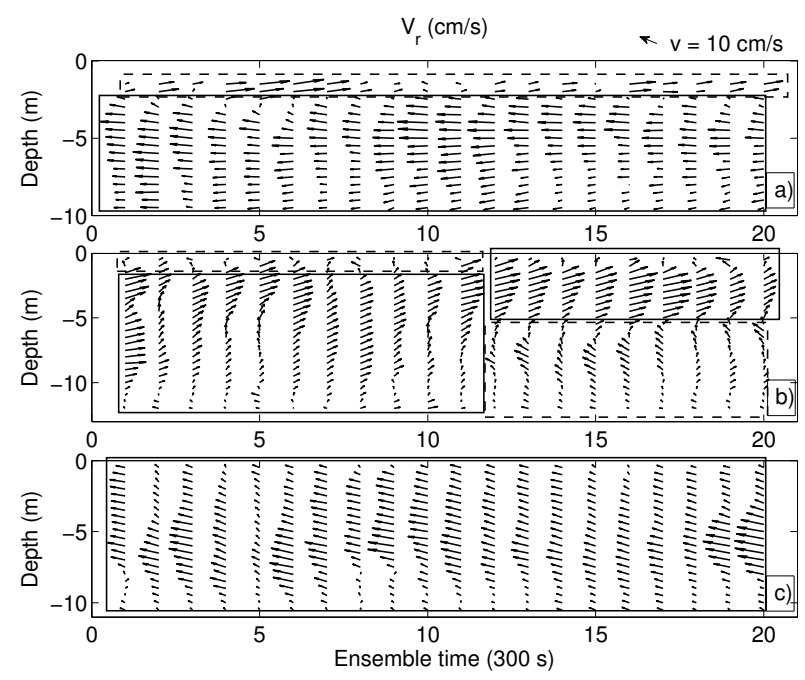

Figure 4: Profiles of radial velocities $\left(v_{r}\right)$ along the axis between the instrument and the plume (entering flow in continuous-line boxes, and leaving flow in dotted ones). a) Data by A02_W, 2002-12-11. b) Data by A03_W, 2003-09-02. c) Data by A03_E, 2003-09-02.

\section{Results and discussion}

\subsection{The Dataset}

The data quality control was the first step of the data processing to select proper periods in the timeseries.

The pitch and roll data from ADCP timeseries confirmed that the instrument did not change position during deployments. In spite of the changes in seabed morphology, all possible errors due to beam slant were excluded during our recording period. The bins at the sea/air interface were necessarily removed before any further data processing to avoid side lobe interference.

We considered two possible sources of error in the remaining dataset: the failure of the basic ADCP homogeneity assumption and the anomalies in backscatter due to bubbles.

The standard deviation of the error velocity was considered a proxy for inhomogeneous velocity fields over beams and was calculated for every bin aiming to locate time ensembles when the whole water column properties fulfilled the ADCP basic assumption.

The ADCP backscatter data were processed to find the scattering anomalies. The difference between the maximum and the minimum of the ADCP backscatter data in every time interval was calculated for 4 beams and compared to the total maximum of the series. This was an experimental assumption (Gilcoto et al., 2009) already used to remove data affected by external sources of error (e.g. fishes) and can be considered a non-random error estimate. In our case, the limit proposed by Gilcoto (20\% of the max) was too restrictive (only $0.5 \%$ of the A02_W data were acceptable). So we doubled the limit, testing the difference against the $40 \%$ of the maximum. The pings we considered free of errors increased approximately to $52 \%$ of the A02_W data.

The raw backscatter values were corrected for the beam attenuation starting from the echo amplitude. We modified the filter $B$, already used by Linke et al. (2010), multiplying data by $10^{-4}$ to isolate echoes and multiplying B for our quality limits, such as

$$
I=B 0.4 \max \left(E A_{i}\right) 10^{-4}
$$

with $I$ and $E A_{i}$ the filtered and the $i_{t h}$ backscatter amplitudes $(\mathrm{dB})$, respectively.

Removing measurements with a high standard deviation and the bubble scatters we obtained:

i) an indication of the times with high gas fluxes or changes in plume dynamics when scattering was higher;

ii) a reduced dataset measuring the homogeneous-amongbeams current dynamics in the full water column;

iii) a non quantitive estimation of the inhomogeneous current velocity from high standard deviation data.

In standard current measurements the components $u$ and $v$ of the currents are recorded such that $u$ is the horizontal component of flow in the East-West direction and $v$ is the horizontal component in the North-South direction. In our case $u$ and $v$ were rotated to highlight the components of velocities along (radial velocities, $v_{r}$ ) and perpendicular to the instrument and the plume section (tangential velocities, $v_{t}$ ). The A02_W and the A03_E data were rotated $34^{\circ}$ clockwise and $45^{\circ}$ counterclockwise, respectively. The A03_W data were not rotated, since the instrument was almost oriented to the new axis.

\subsection{Backscatter}

In 2002, the critically high values of backscatter were found only occasionally in the timeseries and the near field was often free of bubbles. The large bubbles were dominant and the plume was visibly separated from seawater by a wall of bubbles trapped into the ascending plume. A high scattering layer was found at mid-depth with the core situated at approximately $4 \mathrm{~m}$ depth (fig. 3). Plotting the backscatter amplitudes and the water pressure timeseries, recorded by ADCP as ancillary data, an opposite trend was found, similarly to what had already been described for the temperature near other vents (Johnson and Tunnicliffe, 1985; Aliani et al., 2004).

More scattering was found in the water column when the water pressure was at minimum so data during high pressure periods had been selected.

In 2003 two instruments were available. Bubble clouds were found from 6 to $8 \mathrm{~m}$ depth on both sides of the plume. Divers observed smaller bubbles diffused in the water column than in the previous year.

\subsection{Water currents}

Radial $\left(v_{r}\right)$ and tangential $\left(v_{t}\right)$ velocity profiles around the bubble plume had been calculated both from 2002 and 2003 measurements using 20 contiguous ensembles free of bubbles with low error velocity (ADCP basic assumption fulfilled). Results have been reported in fig. 4 and fig. 5 respectively.

Ensembles with high error velocity were considered turbulent and impossible to measure with our ADCP settings (EX11111). For future deployments in comparable environments, we suggest data recording using ADCP setting EX00000. Doppler velocities along each beam direction can be 




Figure 5: Profiles of tangential velocities $\left(v_{t}\right)$ orthogonal to the axis between the instrument and the plume (clockwise flowing current in the continuous-line boxes, counterclockwise in the dotted ones). a) Data by A02_W, 2002-12-11. b) Data by A03_W, 2003-09-02. c) Data by A03_E, 2003-09-02.

stored separately and data can be reprocessed using procedures different from the factory default. At the time of our deployments this advanced use of ADCP was not known (Nystrom et al., 2007; Sousa, 2007; Gilcoto et al., 2009).

In 2002 (A02_W), the water column in the near field of the gas plume was well stratified. Two layers with different circulation were found (fig. 4 and 5a). These layers, separated by a zero velocity interface, corresponded to two vortexes with opposite rotation that entrained and detrained water.

The upper vortex from surface down to about $3 \mathrm{~m}$ depth had $v_{r}$ currents leaving the plume and $v_{t}$ component rotated counterclockwise. It corresponded to the submerged portion of the surface diverging waves created by gas escaping in the atmosphere, already reported by Aliani et al. (2010) and shown on fig. 2 .

In the lower vortex, water entered the plume with maximum velocity at $5 \mathrm{~m}$ depth. Clockwise rotation had been measured all over this layer. Average $v_{r}$ and $v_{t}$ velocities were $7.6( \pm 0.5)$ and $6.0( \pm 0.5) \mathrm{cm} \mathrm{s}^{-1}$. The speed at the interface between the two layers at approximately $4 \mathrm{~m}$ depth was zero.

In 2003 total gas fluxes reduced to one order of magnitude compared to 2002. Average current speeds on the western side were $1.56( \pm 0.5) \mathrm{cm} \mathrm{s}^{-1}\left(v_{r}\right)$ and $2.02( \pm 0.5) \mathrm{cm} \mathrm{s}^{-1}\left(v_{t}\right)$. Highest values were usually at approximately $4 / 5 \mathrm{~m}$ depth and only few inversions in rotations with low speed had been found (fig. 5). Average speeds on the eastern side were $3.38( \pm 0.5) \mathrm{cm} \mathrm{s}^{-1}$ $\left(v_{r}\right)$ and $4.02( \pm 0.5) \mathrm{cm} \mathrm{s}^{-1}\left(v_{t}\right)$.

On the western side (A03_W) stability of the two layers structure was still found, but the system was not as stable over time as it was in 2002 .

In the first eleven time ensembles, the clockwise deeper vortex had been found again and entrainment of seawater into the gas plume took place all over the water column. The surface vortex was thinner and less energetic. A strong surface $v_{r}$ diverging component was not identified.
In the remaining time ensembles, directions opposite to 2002 had been measured. A counterclockwise vortex was found on the bottom and $v_{r}$ component was directed away from the plume. From surface down to $5 \mathrm{~m}$ depth water entered with clockwise rotation. The zero $v_{r}$ layer was at approximately $5 \mathrm{~m}$ depth.

On the eastern side (A03_E), two layers were not measured and current direction was clockwise and directed towards the gas column all over the water column. Distribution of $v_{r}$ intensity over depth profile had highest values at approximately $5 \mathrm{~m}$ depth.

Some theoretical models (Asaeda and Imberger, 1993; Chen and Cardoso, 2000) suggested that detrainment takes place with surface quasi-horizontal jets when fluxes are high, as we found in 2002. When fluxes reduce, many smaller detrainment jets may form. Laboratory experiments (Espa et al., 2010) evidenced that clockwise and counter-clockwise surface eddies may alternate around the core of a bubble plume. When fluxes were low, unsteady detrainment events should also be considered to explain changes over time (Asaeda and Imberger, 1993).

On 2003-09-03, data were recorded at the same spot with the same instrumental settings of the day before but only 10 acceptable bins were found. We rejected this dataset.

\subsection{The model}

In an ascending plume core, bubbles transport fluids upward and entrain surrounding water. In shallow vents, gas escapes in the atmosphere and water is detrained and spread horizontally at certain levels to balance buoyancy (Asaeda and Imberger, 1993).

Many theoretical models describing gas plume dynamics in underwater near and far fields exist (Leifer and Patro, 2002; McGinnis et al., 2004; Bendtsen et al., 2013). The 'nonuniform return flow' model had been selected (Brevik and Kristiansen, 2002) to describe the two layer system we studied.

The model states that i) bubbles increase their size during their ascent in a water column and ii) at a depth called the Stagnation Line (SL) they break into a large number of smaller bubbles with a loss of energy that generates a reversal in the direction of the flow.

SL profile and depth had been described using the environmental properties and coefficients reported in table 1. SL depths and current velocity had been determined according to the model's equations. They had been recalled here as eq. 2, 3, 4 , with $m$ and $k$ the momentum and spreading coefficients, erf the error function, $D$ the plume height, $x$ the horizontal distance from plume center, $h(x)$ the SL depth and $z$ the depth.

$$
\begin{gathered}
u=\frac{m}{\sqrt{D}} \sqrt{\frac{D}{x}} \exp \left(-\frac{z^{2}}{(k x)^{2}}\right)-\frac{k m}{2 \sqrt{D}} \sqrt{\frac{x \pi}{D}} \operatorname{erf}\left(\frac{D}{k x}\right) \\
w=\frac{k m}{4 \sqrt{D}}\left(\frac{D}{x}\right)^{\frac{3}{2}}\left[-x \frac{\sqrt{\pi}}{D} \operatorname{erf}\left(\frac{z}{k x}\right)+\frac{x z \sqrt{\pi}}{D^{2}} \operatorname{erf}\left(\frac{D}{k x}\right)\right. \\
\left.+\frac{4 z}{D k}\left(\exp \left(-\frac{z^{2}}{(k x)^{2}}\right)-\exp \left(-\frac{D^{2}}{(k x)^{2}}\right)\right)\right]
\end{gathered}
$$




\begin{tabular}{lcccc}
\multicolumn{5}{c}{ Table 1: Variables used in the model } \\
\hline Name & symbol & SL Model & $2002-12-11$ & $2003-09-02$ \\
\hline Momentum coef. & $\mathrm{m}$ & 1 & 2.5 & 3.6 \\
Spreading coef. & $\mathrm{k}$ & 0.18 & 0.3 & 0.2 \\
Plume height $(\mathrm{m})$ & $\mathrm{D}$ & 1 & 15 & 13 \\
Gas flux $\left(\mathrm{m}^{3} \mathrm{~s}^{-1}\right)$ & $\mathrm{Q}$ & 0.00341 & 6.9 & 0.8 \\
\hline
\end{tabular}

$$
\frac{h(x)}{D}=0.125\left(1+\frac{x}{D}\right), x \leq 3 D
$$

Horizontal distribution of modeled currents and SL depths had been reported in fig. 6. Two layers in the water column with opposite current directions and the depth of SL have been well identified using environmental conditions measured in 2002 and 2003. Depths of SLs were 3 and $4 \mathrm{~m}$ respectively, which is consistent with the high scattering bubble layer identified by ADCPs.

The model described two layers system with surface current detraining from the plume and subsurface water entraining into the plume. Only minor changes were found in modelling after using 2002 and 2003 environmental parameters.

Fig. 7 shows the comparison between data and model results.

For the 2002 experiment, the model well described measurements. In A03_W dataset two different periods were found and our model fitted just up to the eleventh ensemble. The other part, with an inverted dynamics, didn't fit this model. In the A03_E near field, surface inversion of current direction was modeled but it was not measured.

The model better describes dynamics at horizontal distances comparable to $1 / 2$ of water depth (Brevik and Kristiansen, 2002), so we can consider reliable results about $4 / 6 \mathrm{~m}$ distance from the gas plume, i.e the same distance where the data and the model matched in 2002. In 2003 the flux reduced by one order of magnitude and the effects on the surrounding environment were visibly weaker. At $5 \mathrm{~m}$ distance two layers were only partially measured and $8 \mathrm{~m}$ distance from the core plume was probably too far to be considered into the near field.

\section{Conclusions}

A description of the effects of gaseohydrogeothermal plume in the marine near field during a paroxysmal phase has been presented. ADCP data collected at Panarea in 2002 and 2003 had been reprocessed and tested against theoretical models.

- ADCP was used in a unusual environment where standard ADCP measurements have critical issues that traditionally suggest to avoid using this instrument. We applied error velocity and backscatter analysis in processing sequences, obtaining error-free ensembles to describe water and plume dynamics. Useful data from ADCP even in conditions where basic ADCP assumptions and bubble scattering would have excluded its use had been achieved.

- Due to the complex environment and the factory settings we used, some information were lost during data processing. Better analysis could have been possible recording

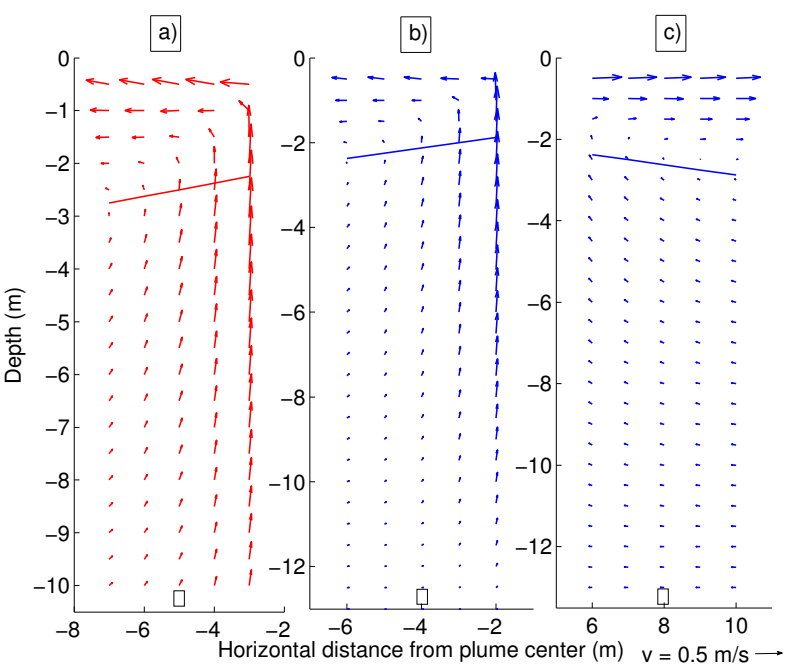

Figure 6: Current values and SL depths from model in 2002 (red arrows) and 2003 (blue arrows), describing the environment around the instruments. Positions of ADCPs superimposed on X-axis: a) A02_W, b) A03_W, c) A03_E.

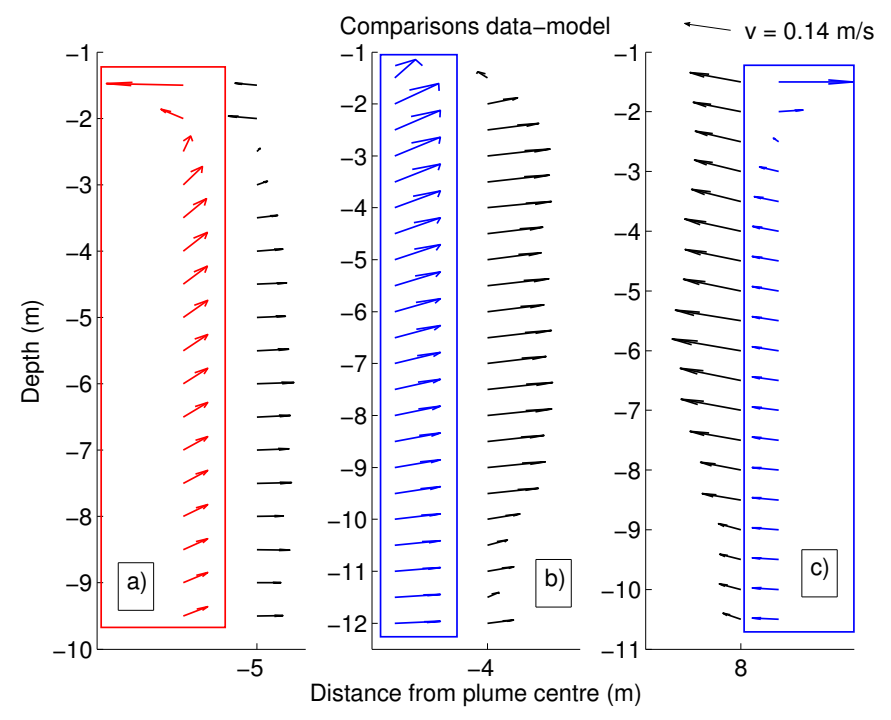

Figure 7: Data collected (black arrows) were compared with model results (coloured arrows). a) Data from A02_W. b) Data from A03_W. c) Data from A03_E. Model was confirmed for A02_W and the part of A03_W where surface vortex had been measured, but it was not for part of A03_W and A03_E when model described a surface vortex that was not measured. 
raw radial Doppler data from each beam. For future deployments in comparable environments, we suggest data recording using ADCP setting EX00000 instead of the default. Custom made algorithms and scripts available from the literature now may also be used for data processing for future applications.

- Bubble clouds diffused in the water column affected data quality. However bubble free periods were also recorded and it was possible to select periods when data could be processed.

- After echo backscatter filtering, bubble clouds were identified at intermediate depth and two layers with opposite current direction were observed.

Two possible scenarios have been described:

- an high dynamic situation with visible surface diverging rings of waves, entrainment on the lower part of the gas column, detrainment in the upper part and a stagnation line at mid depth where currents were close to zero and most of gas bubbles spread laterally;

- a low dynamic situation with water entraining into the gas plume at all depths and no surface rings of diverging waves.

Reasons for these different dynamics may be ascribed to reduction of gas fluxes (one order of magnitude lower in 2003) as well as different distances of the ADCPs from the gas source during the two experiments.

- Pattern described by ADCP data has been compared to the results of 'non-uniform return flow' model. The SL profile from ADCP data matched the model and the Stagnation Line depth can be inferred from SL model to forecast consequences for geochemical reactions in the water column and the transport of particles in hydrothermal systems.

Data from ADCP deployed on 2003 to the $\mathrm{W}$ of the vent matched the model better than those to the E. When flux were high, detrainment took place with surface quasihorizontal jet. This is the best scenario for SL model. When fluxes reduced, many smaller detrainment jets may have formed and clockwise and counter-clockwise surface eddies may alternate around the core of a bubble plume. This is a situation only partly described by SL model, also considering that unsteady situation may also occur. Distance of the instruments from the plume as well as crater morphology that forced the gas flux to the South East may also be important.

Gas eruption at shallow vents are dominated by turbulence that drives complicated detrainment-entrainment dynamics and gas bubbles lateral diffusion. Advection diffusion equations are inadequate to describe processes of hydrothermal fluids mixing with seawater because bubbles create variable circulation patterns. Quantitative estimation of entrainment-detrainment of seawater is important for geochemical processes into the plume but it is not possible to calculate it, before full description of gas plume interactions has been provided. Depth of Stagnation line is important to quantify where and when entrainmentdetrainment take place in the water column and can be measured and calculated from SL model.

We described here changes in seawater dynamics that took place in the near field of a gas column during an underwater gas eruption. Transient external forcing, changes due to rotational effect of the gas column and time evolution at scales larger than our dataset may also create unknown scenarios different from those we described here. Laboratory and field investigations with different ADCP settings may help to describe patterns not identified here.

\section{Acknowledgments}

We wish to thank G. Biasini and A. Giordano of Communication Technology, for their suggestions concerning ADCP setting and uses. We thank also the Italian Coast Guard for their assistance during the experiments.

\section{References}

Aliani, S., Bianchi, C.N., Cocito, S., Dando, P.R., Meloni, R., Morri, C., NieMeyer, A., Peirano, A. and Ziebis, W. (1998), A map of seagrass meadows in Paleochori bay (Milos island, Greece), a marine area with Hydrothermal activity, Rapp. Comm. Int. Mer. Medit., 35, 512-513.

Aliani, S., Meloni, R., Dando, P.R. (2004), Periodicities in sediment temperature time-series at a marine shallow-water hydrothermal vent in Milos Island (Aegean Volcanic arc, Eastern), Journal of Marine Systems, 46(1), 109-119.

Aliani, S., Bortoluzzi, G., Caramanna, G. and Raffa, F. (2010), Seawater dynamics and environmental settings after november 2002 gas eruption off Bottaro (Panarea, Aeolian Islands, Mediterranean Sea), Cont. Shelf Res., 30(12), 1338-1348.

Allard,P., Maiorani, A., Tedesco, D., Cortecci, G., Turi, B. (1991), Isotopic study of the origin of sulfur and carbon in Solfatara fumaroles, Campi Flegrei caldera, Journal of Volcanology and geothermal research, 48(1), 139-159, doi:10.1130/G31901.1.

Anzidei, M., Esposito, A., Bortoluzzi, G. and Degiosa, F. (2005), The high resolution map of the exhalative area of Panarea (Aeolian Is., Italy), Annals of Geophysics, 48(6), 899-921.

Asaeda T. and Imberger J. (1993), Structure of bubble plumes in linearly stratified environments, Journ. Fluid Mechanics, 249, 35-57

Bayona, J., Monjonell, A., Miquel, J., Fowler, S. and Albaigés, J. (2002), Biogeochemical characterization of particulate organic matter from a coastal hydrothermal vent zone in the Aegean Sea, Org. Geochem., 33(12), 1609-1620, doi:10.1016/S0146-6380(02)00175-4.

Bendtsen, J., Gustafsson, K.E., Lehtoranta, J., Saarijarvi, E., Rasmus, K., and Pitkanen, H. (2013), Modeling and tracer release experiment on forced buoyant plume convection from coastal oxygenation, Boreal Env. Research, 18, 37-52, ISSN 1239-6095.

Brevik, I., and Kristiansen, O. (2002), The flow in and around air-bubble plumes, Int. J. Multiphase Flow, 28, 617-634.

Caliro, S., Caracausi, A., Chiodini, G., Ditta, M., Italiano, F., Longo, M., Minopoli, C., Nuccio, P.M., Paonita, A. and Rizzo, A. (2004), Evidence of a recent input of magmatic gases into the quiescent volcanic edifice of Panarea, Aeolian Islands, Italy, Geophys. Res. Lett., 31, L07,619, doi:10.1029/2003GL019359.

Capaccioni, B., Tassi, F., Vaselli, O., Tedesco, D., Poreda, R. (2007), Submarine gas burst at Panarea Island (southern Italy) on 3 November 2002: A magmatic versus hydrothermal episode., J. Geophys. Res., 112, B5, doi:10.1029/2006JB004359. 
Chen, MH., and Cardoso, S.S. (2000), The mixing of liquids by a plume of low-Reynolds number bubbles, Chemical Engineering Science, 55, (14), 2585-2594.

Dando, P.R., Aliani, S., Arab, H., Bianchi, C.N., Brehmer, M., Cocito, S., Fowler, S.W., Gundersen, J., Hooper, L.E., Kolbl, R., Kuever, J., Linke, P., Makropoulos, K., Meloni, R., Miquel, J.C., Morri, C., Muller, S., Robinson, C., Schlesner, H., Sievert, S., Stohr, R., Stuben, D., Thomm, M., Varnavas, S. and Ziebis, W. (2000), Hydrothermal studies in the Aegean Sea, Phys. Chem. Earth Pt. B, 25(1), 1-8.

Dialti, L., De Lucia, A., Marziani, F., Niccolini, A., Zeppetella, A., di Fava, M., Guideri, M., Carmisciano, C., Cocchi, L., Muccini, F., Bortoluzzi, G., and Aliani, S. (2013), Rapporto sulle attivitá geofisiche, oceanografiche e di campionamento durante la crociera PANSTR12 con nave Aretusa: Isole Eolie (Stromboli, Panarea, Salina) (2012-0630-2012-07-14), INGV Reports, 245, 1-26.

De Biasi, A.M., Aliani, S., (2003), Shallow-water hydrothermal vents in the Mediterranean sea: stepping stones for Lessepsian migration?, Hydrobiologia 503 (1-3), 37-44.

Eaton, J.W., Bateman, D., and Hauberg, S. (2008), GNU Octave Manual Version 3, Network Theory Limited.

Espa, S., Caramanna, G., Bouché, V. (2003), Field study and laboratory experiments of bubble plumes in shallow seas as analogues of subseabed CO2 leakages, Applied Geochemistry, 25, 696-704.

Esposito, A., G. Giordano, and M. Anzidei (2006), The 2002-2003 submarine gas eruption at Panarea volcano Aeolian Islands, Italy: volcanology of the seafloor and implications for the hazard scenario, Mar. Geol., 227, 119-134.

German C. and Von Damm K.L (2006) Hydrothermal processes In:The Oceans and Marine Geochemistry, eds: Elderfield, H,D,. Holland, K. and Turekian K., Elsevier.

Gilcoto, M., Jones, E. and Faria-Busto, L. (2009), Robust Estimations of Current Velocities with Four-Beam Broadband ADCPs, J. Atmos. Ocean. Technol., 26, 2642-2654, doi:10.1175/2009JTECHO674.1.

Gordon, R. (1996), Acoustic Doppler Current Profiler Principles of Operation A Practical Primer. Second Edition for Broadband ADCPs, RD Instruments 9855 Businesspark Ave. San Diego, California 92131 USA

Heinicke, J., Italiano, F., Maugeri, R., Merkel, B., Pohl, T., Schipek, M., Braun, T. (2009), Evidence of tectonic control on active arc volcanism: The Panarea-Stromboli tectonic link inferred by submarine hydrothermal vents monitoring (Aeolian arc, Italy). Geophys. Res. Lett. 36, L04301.

Jackson, D.R., Jones, C.D., Rona, P.A., Bemis, K.G. (2003), A method for Doppler acoustic measurements of black smoker flow fields, Geochemistry Geophysics Geosystem, 4(11), 1-12, doi: 10.1029/2003GC000509.

Johnson, H.P. and Tunnicliffe, V. (1985), Time-series of measurements of hydrothermal activity on northern Juan De Fuca Ridge., Geophysical Research Letters, 12, 685-688.

Kadar, E., Fisher, A., Stolpe, B., Harrison, R.M., Parello, F., Lead, J. (2012), Metallic nano particle enrichment at low temperature, shallow $\mathrm{CO}_{2}$ seeps in Southern Italy, Marine Chemistry, 140-141, 24-32, doi: 10.1016/j.marchem.2012.07.001.

Klinkhammer, G.P., Chin, C.S., Keller, R.A., Dahlmann, A., Sahling, H., Sarthou, G., Petersen, S., Smith, F., Wilson, C. (2001), Discovery of new hydrothermal vent sites in Bransfield Strait, Antarctica, Earth and Planetary Science Letters, 193, 395-407.

Leifer, I., and Patro, R. (2002), The bubble mechanism for methane transport from the shallow sea bed to the surface: A review and sensitivity study, Cont. Shelf Res., 22, 2409-2428.

Leifer, I., Clark, J.F., and Chen, R.F. (2000), Modifications of the local environment by natural marine hydrocarbon seeps, Geophys. Res. Lett., 27(22), 3711-3714.

Linke, P., Sommer, S., Rovelli, L. and McGinnis, D.F. (2010), Physical limitations of dissolved methane fluxes: the role of bottomboundary layer processes, Mar. Geol., 272(1-4), 209-222, doi: 10.1016/j.margeo.2009.03.020.

Lupton, J.E. (1995), Hydrothermal plumes: near and far fields, In: Humphries, S. E., Zierenberg, R. A., Mullineaux, L. S. and Thomson, R. E. (eds), Seafloor Hydrothermal Systems: Physical, Chemical, Biological and Geological Interactions. Geophysical Monograph,
91(AGU), Washington D.C. 317-346.

MATLAB (2011), version 7.13 (R2011), The MathWorks Inc., Natick, Massachusetts.

McDougall, T.J. (1978), Bubble plumes in stratified environments, Journal of Fluid Mechanics, 85, pp 655-672 doi: $: 10.1017 /$ S0022112078000841

McGinnis, D.F., Lorke, A., Wüest, A., Stöckli, A. and Little, J.C. (2004), Interaction between a bubble plume and the near field in a stratified lake, Water Resources Res., 40(W10206) doi: 10.1029/2004WR003038.

Nystrom, E., Rehmann, C., Asce, M. and Oberg, K. (2007), Evaluation of mean velocity and turbulence measurements with ADCPs, J. Hydraul. Eng.-Asce, 133(12), 1310-1318, doi:10.1061/(ASCE)07339429(2007)133:12(1310).

O’Hara, S.C.M., Dando, P.R., Schuster, U., Bennis, A., Boyle, J.D., Chui, T.W., Hatherell,V.J., Niven, J. and Taylor, L.Y. Gas seep induced interstitial water circulation: observations and environmental implications, Cont. Shelf. Res., 15(8), 931-948, doi:0278-4343(94)00050.

Pichler, T., Veizer, J., Hall, G.E.M. (1999), The chemical composition of shallow-water hydrothermal fluids in Tutum Bay, Ambitle Island, Papua New Guinea and their effects on ambient seawater, Marine Chemistry, 64(3), 229-252.

Robinson, C. (2000), Plankton gross production and respiration in the shallow-water hydrothermal systems of Milos, Aegean Sea, J. Plankton Res., 22(5), 887-906.

Rona, P.A., Bemis, K.G., Jones, C.D., Jackson, D.R., Mitsuzawa, K. and Silver, D. (2006), Entrainment and bending in a major hydrothermal plume, Main Endeavour Field, Juan de Fuca Ridge, Geophysical Research Letters, 33, doi:10.1029/2006GL027211.

Solomon, E.A., Kastner, M., MacDonald, I.R. and Leifer, I. (2009), Considerable methane fluxes to the atmosphere from hydrocarbon seeps in the Gulf of Mexico, Nat. Geosci., 2, 561-565, doi:10.1038/ngeo574.

Sousa, A. (2007), The use of ADCPs to measure turbulence and SPM in shelf seas, in 2nd International conference and exhibition on Underwater Acoustic Measurements: technologies and results, 25-29 June 2007, Heraklion, Crete, 25-29 June 2007.

Svensson, E., Skoog, A. and Amend, J.P. (2004), Concentration and distribution of dissolved amino acids in a shallow hydrothermal system, Volcano Island (Italy), Organic Chemistry, 35(9), 1001-1014, doi: 10.1016/j.orggeochem.2004.05.005.

Tarasov, V.G., Gebruk, A.V., Mironov, A.N. and Moskalev, L.I. (2005), Deep-sea and shallow-water hydrothermal vent communities: two different phenomena?, Chemical Geology, 224, 5-39, doi: 10.1016/j.chemgeo.2005.07.021.

Thiermann, F., Akoumianaki, I., Hughes, J. and Giere, O. (1997), Benthic fauna of a shallow-water gaseohydrothermal vent area in the Aegean Sea (Greece), Marine Biology, 128, 149-159.

Tivey, M., Bradley, A., Joyce, T. and Kadko, D. (2002), Insigths into tide-related variability at seafloor hydrothermal vents from time-series temperature measurements, Earth Planet. Sci. Lett., 202, 693-707.

Wang, D., Wijesekera, H., Teague, W., Rogers, W. and Jarosz, E. (2011), Bubble cloud depth under a hurricane, Geophys. Res. Lett., 38, L14,604.

Wenzhofer, F., Holby, O., Glud, R.N., Nielsen, H.K. and Gundersen, J.K. (2000), In situ microsensor studies of a shallow-water hydrothermal vent st Milos, Greece, Marine Chemistry, 69, 43-54.

Wessel, P. and Smith, W.H.F. (1995), New version of the Generic Mapping Tools released, Trans. Am. Geophys. Union (EOS), 76, 329. 